\title{
Collaborative Care model in mental health. Scope and experiences after three years of activity in Mexico City
}

\author{
Valerio Villamil-Salcedo ${ }^{1}$, Blanca E. Vargas-Terrez ${ }^{2}$ and Adriana Díaz-Anzaldúa $^{1}$ \\ ${ }^{1}$ Investigator from Department of Clinical Research, National Institute of Psychiatry Ramón de la Fuente Muñiz, \\ Mexico City, C.P. 14370, Mexico \\ ${ }^{2}$ Chief of Community Psychiatry Service from Department of Clinical Services, National Institute of Psychiatry Ramón \\ de la Fuente Muñiz, Mexico City, C.P. 14370, Mexico
}

\begin{abstract}
Aim: The aim of this study was to evaluate the experience of the Collaborative Care model with general practitioners (GPs) for diagnosis and treatment of depression and anxiety disorders in primary care centers (PCC). Background: For many years, different ways to address mental health problems in primary care settings have been evaluated. However, there is still debate over how to treat psychiatric conditions in such a context. Method: A cross-sectional design was used. The study was conducted in two consecutive studies in six PCC that serve marginalized population in Mexico City. In the first study, cases were interviewed, diagnosed, and treated by a psychiatrist. In the second study, Collaborative Care model was used and GPs were trained; psychiatrists diagnosed and treated patients but GPs discussed the symptoms and treatment of the patients with the psychiatrist. Findings: First study: 18 patients with depressive and/or anxiety disorders were interviewed; these cases were not discussed between the GPs and the psychiatrist. Second study: psychiatrists and GPs conducted joint interviews and cases were discussed. From the 399 evaluated individuals, 38.94\% were diagnosed with a depressive disorder. After the Collaborative Care model was applied, GPs were more aware about mental health problems and they were more interested in the identification of these conditions in PCC. Replication studies will help confirm the effectiveness of this model.
\end{abstract}

Key words: anxiety; community mental health; consultation-liaison; depression

Received 12 October 2016; revised 8 December 2016; accepted 13 January 2017; first published online 21 February 2017

\section{Background}

The need to provide mental healthcare in primary care settings is based on several factors. First, psychiatric disorders have a large impact; as a group, they are very common and they are associated with disability and high comorbidity and, in some cases with premature death (Medina-Mora et al., 2003; Borges et al., 2006; Lara et al., 2007;

Correspondence to: Valerio Villamil-Salcedo, Department of Clinical Research, Nacional Institute of Psychiatry Ramón de la Fuente Muñiz. Mexico City. Mexico. Email: valemil_2000@ yahoo.com

(C) Cambridge University Press 2017
World Health Organization, 2010). Second, medical care has a lower cost in primary as opposed to Secondary or Tertiary Healthcare (Gask et al., 1997). Third, there is a reduced number of psychiatrists worldwide, which contrasts with the high demand for attention in Mexico. The Mexican Psychiatric Association reported having 2452 specialists in this country in 2011. However, up to half of them are not certified (Villamil-Salcedo, 2011). According to a more recent study, there were almost 4000 psychiatrists in 2012 (about 3.47 psychiatrists/ 100000 individuals). These numbers are lower than the international average, of 4.1/100 000 inhabitants (Heinze et al., 2012). 
The above figures reflect the relevance of increasing mental healthcare; they show that psychiatrists are not capable of providing all the care, given that there is a shortage of these professionals. In addition, general practitioners (GPs) are not trained to identify mental disorders and this promotes one of the many gaps in mental health care (World Health Organization, 2010; Berenzon et al., 2013).

The alternative for the prevention and community management of mental disorders is to include mental health teams: GPs, nurses, social workers, psychologists, and other professionals (anthropologists, sociologists, etc.). However, there is still debate on the most appropriate model for the care of mental disorders at this level (Gask et al., 1997; Villamil-Salcedo, 2011).

Bower and Gilbody (2005) reviewed many models that have been tested and highlighted four of them as different forms improving quality of care: (1) Training primary care team. It refers to providing knowledge and skills on mental health to primary care practitioners; (2) Consultationliaison. It involves mental health specialists within an educational relationship with primary care physicians in order to provide care to patients; (3) Collaborative Care. It involves both training and consultation-liaison of those working with patients in primary care. It includes screening, education of patient, changes in routine care, and use of information technology; (4) Replacement/ referral. In this model, the psychiatrist has the primary responsibility for the management and treatment of mental disorders. The authors conclude that no single model is ideal or has a greater cost-effectiveness.

On the other hand, it has been observed that early diagnosis and treatment are associated with better outcome and prognosis of individuals with mental disorders; thus, prevention is the cornerstone of the community care of psychiatric disorders (this term refers to the mental healthcare in the primary care) (Villamil-Salcedo, 2011).

The Collaborative Care model was selected based on the theoretical model of Katon et al. (2001) for patients with chronic diseases, especially type-2 diabetes and hypertension. As mentioned before, the model involves training of health personnel and consultation/liaison by a team of quasi-specialists (also called managers) who work with the patient and with the advice of GPs in
Primary Care Centers (PCC) in order to improve the quality of healthcare (Katon et al., 2001; Bower and Gilbody, 2005). The Katon model was adapted to this study where we included a psychiatrist like a part of the quasi-specialist team.

A model of Collaborative Care aimed at the identification and management of the most frequent mental disorders was designed and adapted to the needs of our population. This was done to assess the feasibility of alternative models of care for persons with mental disorders in primary care. In a previous study (Vargas-Terrez et al., 2012), barriers and frequent problems in the implementation of a new model of care for mental health in primary settings were identified. The tested model considered the findings of this previous study.

The aim of this study was to evaluate the experience of the Collaborative Care model with GPs for diagnosis and treatment of depression and anxiety disorders in PCC and the satisfaction of them to work with this model.

\section{Method}

A cross-sectional design was used, conducted in two consecutive studies in six PCC located in the neighborhood of Coyoacan, which work with lowincome population in the South of Mexico City.

\section{PCC and population characteristics}

PCC in Mexico City are divided according to their size into 'T-I,' 'T-II,' and 'T-III,' being T-III the largest; this nomenclature takes into consideration their physical infrastructure, number of staff members, and the number of families it serves. The served population is composed of 2000-10000 families. Staff functions are divided into administrative (PCC director, chief nurse, etc.), community (home visitors), and medical care (for outpatients). Our study focused on medical care for outpatients from three 'T-II' and two 'T-III' PCC. 'T-I' PCC were not considered because they do not have a Self-Help Group. From the six PCC, three of them served as headquarters where the psychiatrist met with the medical care team PCC once a month. We used the next nomenclature: PCC-A refers to a 'T-II' headquarters and PCC-B and PCC-C, respectively, refer to two 'T-III' headquarter PCC. 


\section{Features of the Collaborative Care sessions}

Collaborative Care participants were GPs, nurses, social workers, and psychologists who were in direct relation to the Self-Help Group for diabetes, hypertension, and obesity; however, other health professionals (eg, dentists) were also involved. Monthly sessions of $1 \mathrm{~h}$ were held at the established PCC headquarters. The psychiatrist interviewed patients in a single occasion, and then the cases were referred to their physician to discuss them. The cases had been assessed by the psychiatrist and a Medical Postgraduate Student, and they were discussed by the GP. Collaborative Care sessions acted as supervision and monitoring of cases for the GP.

\section{Instruments}

Filter or checklist card: it was based on the Mental Health Gap Action Programme (mhGAP Intervention Guide) of the World Health Organization and it was modified according to the needs of this project (World Health Organization, 2010); it is a short pocket document aimed for GPs at the PCC, so they can have a quick and easy tool for screening patients. It contains basic information in a checklist format for the identification of key symptoms of depression and/or anxiety (Figure 1).

Psychological Distress Scale Kessler 10 (K-10): it is a screening tool that was validated in clinical populations showing high sensitivity and specificity. The instrument has high accuracy, because it can detect up to $87 \%$ of cases of depression and $82.4 \%$ of cases of anxiety. Internal consistency was $\alpha=0.901$ (Vargas-Terrez et al., 2011).

Satisfaction questionnaire for health staff: this questionnaire was made expressly for this research; it consists of open and closed questions assessing staff satisfaction when working with patients with mental disorders, satisfaction when working under this type of model of care, and three Likert-type questions about stigma toward mental illness (Are you afraid to treat a person with mental disorders? Are you easily angry when you treat a person with mental disorders? and in general, are people with mental disorders discriminated against by health personnel (doctors, nurses, social workers, etc.)?

The Collaborative Care model consisted of the following steps:

1. Implementation of K-10 to identify probable cases and supervision, counseling, education, and training of physicians by a psychiatrist who worked closely with the group.

2. Training of health personnel; in order to homogenize the knowledge of GPs regarding psychiatry, a five-topic training (of two hours each topic) once a week in two PCC was proposed; topics were: first day: epidemiology of mental disorders ( $2 \mathrm{~h})$; second day: epidemiology and diagnosis of depression (2h); third day: epidemiology and diagnosis of anxiety disorders ( $2 \mathrm{~h}$ ); fourth day: treatment of depression and anxiety disorders; and fifth day: stigma. In sessions two to four, health personnel worked with vignettes and described the principal symptoms of depression and anxiety disorders. At the end, we applied the satisfaction questionnaire.

3. Screening of probable cases detected by GPs in general practice, in joint sessions. Cases were interviewed by a psychiatrist and by GPs who detected the case; at the end of the session, a clinical diagnosis was established and treatment alternatives were offered to the patient. All the involved health personnel participated in this activity. For this reason, it was called joint interview,' which corresponds to the consultation and liaison components of the model. The session was in charge of the psychiatrist who evaluated patients and who were part of the research group. The aims of the meetings were: (a) Discussions of the cases between GPs and the psychiatrist; (b) Integration of a psychiatric diagnosis; the 'joint interviews' of patients helped to emphasize on the characteristics of the mental examination; and (c) Continuous sensitization of healthcare for patients with mental disorders talking about what they feel when they are in front of them.

\section{Procedure}

Once the protocol was approved by the Ethics and Scientific Committees of an institute specialized in psychiatry, located in Mexico City, a work agreement was made with three headquarter PCC in the neighborhood of Coyoacan, where the Collaborative Care model with personnel was launched (PCC-A, PCC-B, and PCC-C).

Fieldwork was conducted in two consecutive studies: In the first one, we focused on all outpatients seeking care with the GPs from two PCC. This study 

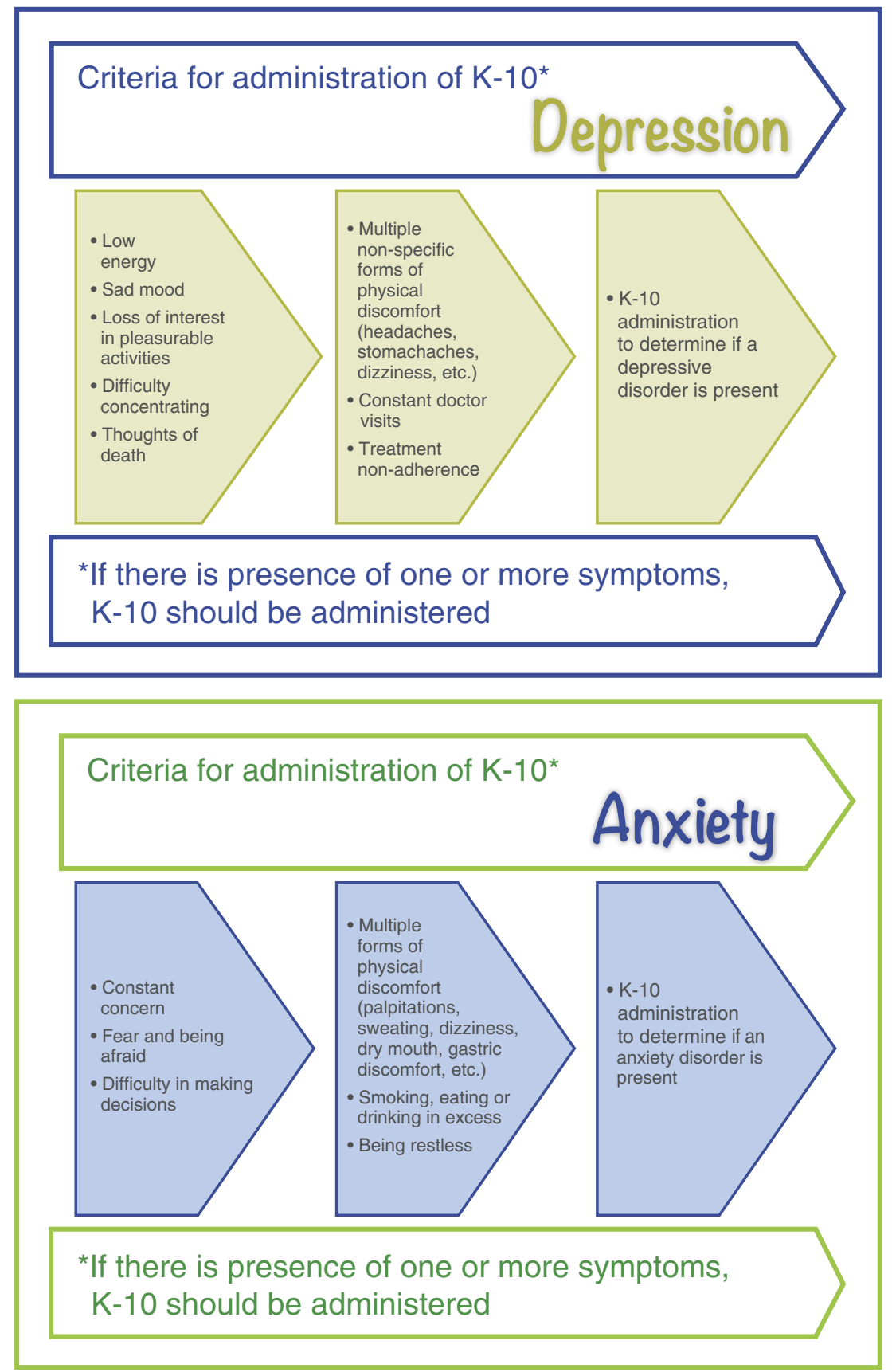

Figure 1 Filter or checklist card.

lasted one and a half years (from January 2010 to June 2011). At the end of this phase, the satisfaction questionnaire was applied to all physicians.
In the second study, the Collaborative Care model was used, and it was conducted with personnel who were working with Self-Help Groups, 


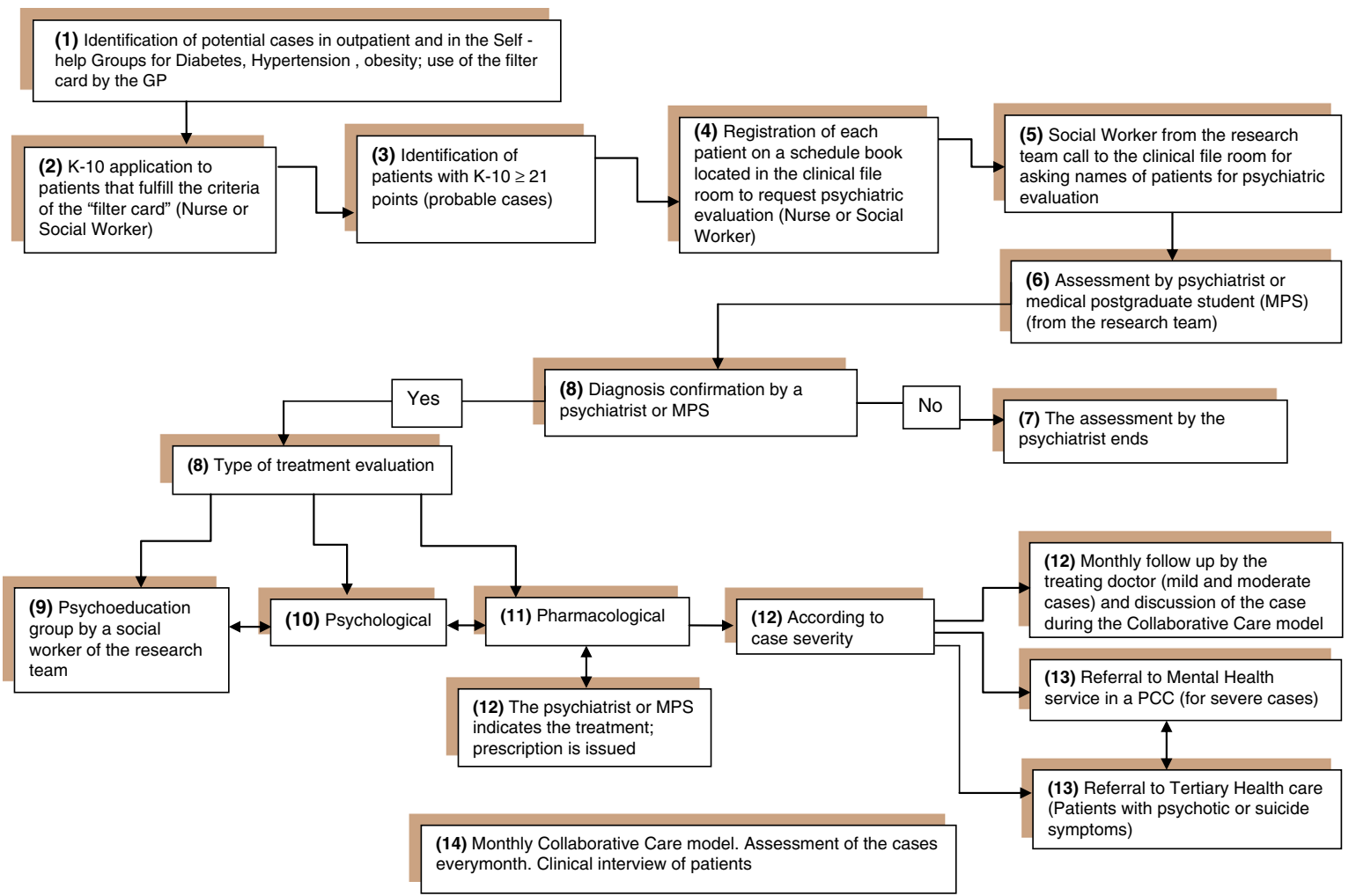

Figure 2 Flowchart for care for patients in primary care centers.

responsible for healthcare and metabolic control of diabetes, hypertension, and obesity. During this phase, four additional PCC joined the study, so this second study was applied at six PCC. The decision to work with diabetic, hypertensive, and obese patients was taken because it was a captive group that met weekly and had continuous evaluations by a health team (Figure 2). While this second study focused primarily on these groups, other outpatients of general medicine who required or requested psychiatric care were not excluded.

The Psychological Distress Scale Kessler-10 (K-10) was applied to all patients in the Self-Help Group; patients who scored over $21 \quad(n=565)$ were evaluated; a psychiatrist and a Medical Postgraduate Student who were part of the research team then assessed each one of them; together they diagnosed and treated the patients (Figure 2). A psychiatrist of our team participated in the study because there was only one psychiatrist in only one PCC in Coyoacan, who scheduled patients who were already registered, but not new cases.

To conduct the sessions of the Collaborative Care model, three PCC headquarters were established for monthly meetings between the personnel in charge of the Self-Help Group and the research team (a social worker and the psychiatrist). The second phase was conducted from July 2011 to October 2012.

For this study a 'filter card' was prepared (Figure 1). Patients who presented any symptoms of the filter card were candidates for the application of K-10 (Figure 2). In addition, a sheet with the contents of the mental examination was sent to the GP, to help him or her guide interviews with patients.

\section{Results}

First study

A total of 24 sessions in the PCC-A were removed from the study (60.0\%) and $28(58.33 \%)$ 
Table 1 First study

\begin{tabular}{lllllc}
\hline Primary care center & Depressive disorder $^{\mathrm{a}}$ & Anxiety disorder $^{\mathrm{b}}$ & Other disorder $^{\mathrm{c}}$ & None & Total \\
\hline PCC 'A' & 7 & 3 & 2 & 2 & 14 \\
PCC ' $\mathrm{B}^{\prime}$ & 4 & 0 & 0 & 0 & 4 \\
\hline
\end{tabular}

Diagnosis of patients assessed during the joint sessions (January 2010 to June 2012).

${ }^{a}$ Major depressive disorder or dysthymia.

${ }^{\mathrm{b}}$ Panic disorder, generalized anxiety disorder, obsessive-compulsive disorder.

${ }^{\mathrm{c}}$ Mental and behavioral disorder due to brain disease, damage or dysfunction or attention deficit/ hyperactivity disorder.

Table 2 Average attendance per joint session

\begin{tabular}{lllllll}
\hline Primary care center & Physicians & $\begin{array}{l}\text { Physicians in } \\
\text { social service }\end{array}$ & Nurses & Psychologists & $\begin{array}{l}\text { Social } \\
\text { workers }\end{array}$ & Other \\
\hline January 2010 to June 2011 & & & & & & \\
$\quad$ PCC 'A' & 3 & 2 & 1 & 0 & 0 & 0 \\
$\quad$ PCC 'B' & 2 & 1 & 3 & 1 & 1 & 4 \\
July 2011 to November 2012 & 4 & 2 & 1 & 0 & 1 & 3 \\
$\quad$ PCC 'B' & 2 & 1 & 1 & 1 & 2 & 1 \\
PCC 'C' & 2 & & 1 & & \\
\hline
\end{tabular}

in the PCC-B. In all, 14 Joint Interviews were conducted by health personnel and the specialist at the PCC-A and four at the PCC-B. The most frequent diagnoses were depressive and anxiety disorders (Table 1).

On average, three GPs and two physicians in social service participated in each session at the PCC-B; the rest of the staff did not attend all sessions. In the PCC-A, the average per session was two GPs and a physician in social service (Table 2).

\section{Second study}

In the second study, 16 Collaborative Care sessions were scheduled in each PCC with personnel in charge of Self-Help Groups of diabetics, hypertensive, and obese patients. Three sessions were canceled at the PCC-B (18.75\%), while only one session was canceled in the PCC-C $(6.25 \%)$.

In this study, an average of four GPs, two physicians in social service, and five other health workers (dentist, nurse, or social worker) participated in the PCC-B during the Collaborative Care model. At the PCC-C, the average was two GP's, a nurse, a psychologist, and two social workers (Table 2). Five joint interviews were conducted in the PCC-C; no patient had a psychiatric diagnosis.
The screening tool K-10 was applied to 747 patients; 565 (70.6\%) were possible cases, and 399 patients agreed to be evaluated by a specialist; a total of 323 patients continued outpatient treatment by their GP. In this group, $38.94 \%$ had a diagnosis of depressive disorder; 76 patients $(13.45 \%)$ were referred to a second or third level because of the severity of their symptoms; only $8.03 \%$ (32 subjects evaluated) with K-10 scores higher than 21 were not cases (Table 3). The average score of the K-10 was 31.34 (565 patients) $($ male $=29.53$; female $=31.44)$.

According to the results on the satisfaction survey, physicians answered that attend one to five patients with a mental disorder in a typical week, being depression and anxiety disorders the most commonly seen; they still do not feel skilled enough when caring for patients with mental disorders. They consider that their own schedule, as these patients demand more time for attention, as well as the lack of pharmacological treatment in the PCC, and their poor training are part of the main barriers to treat such patients. Regarding the Collaborative Care sessions, physicians were very satisfied with the activity and their interest for mental health issues increased.

Regarding the questions of stigma, $29 \%$ of them reported being afraid of treating patients with 
Table 3 Second study

\begin{tabular}{lllllll}
\hline Depressive disorder $^{\mathrm{a}}$ & Anxiety disorder $^{\mathrm{b}}$ & Other $^{\mathrm{c}}$ & None & Reference $^{\mathrm{d}}$ & Not Attended $^{\mathrm{e}}$ & Total \\
\hline $220(38.94 \%)$ & $41(7.26 \%)$ & $30(5.31 \%)$ & $32(5.66 \%)$ & $76(13.45 \%)$ & $166(29.38 \%)$ & $565(100 \%)$ \\
\hline
\end{tabular}

Diagnosis and reference (February 2011 to November 2012).

${ }^{a}$ Major depressive disorder or dysthymia.

b Panic disorder, generalized anxiety disorder, obsessive-compulsive disorder.

${ }^{\mathrm{c}}$ Mental and behavioral disorder due to brain disease, damage or dysfunction, substance abuse/dependence or attention deficit/hyperactivity disorder.

${ }^{\mathrm{d}}$ Major depressive disorder with psychotic symptoms, recurrent depressive disorders, suicidal ideation, personality disorders, dementia, epilepsy.

${ }^{\text {e }}$ Subjects with $\mathrm{K}-10 \geqslant 21$ points who do not attend consultation.

mental disorders; $24 \%$ reported that they get easily angry when they treat a person with a mental disorder; in fact, they avoided this situation, and they tried to spend the minimum time in mental health assessment. In addition, $66 \%$ of the health personnel think that people with mental disorders are discriminated against by most physicians.

\section{Conclusions}

Our results showed that the Collaborative Care model attracted the attention of personnel of the PCC, breaking the paradigm of mental healthcare, when they verified the diagnosis and discussed them with the psychiatrist. This was possible thanks to the support and constant communication between the psychiatrist and the PCC staff in the assessment of patients and in the joint interviews. This was very well received by the staff, who were grateful.

Despite the observed changes in the normal routine of medical care, and benefits of Collaborative Care in PCC personnel and patients, further studies are needed before making a generalized proposal for providing a decisive and efficient care for patients with psychiatric disorders in the primary healthcare. However, we do suggest taking into account the implementation of Collaborative Care model in primary settings for patients with psychiatric conditions. This would limit the stigma of psychiatric disorders and would help perceive psychiatrists as professionals who can give support for the management of such patients in PCC.

Over $50 \%$ of the sessions of the first stage were suspended for several reasons including change of director of the PCC, excessive workload of GPs attending outpatients, health or vaccination week, holidays, lack of coordination between the PCC board and their health staff, etc. 'T-II' and 'T-III' showed the same problems, so they do not have differences between them. However, in the Collaborative Care model (second stage) less sessions were suspended; maybe this change was due to the greater commitment by the personnel.

Our results show that GPs were interested in some activities of Collaborative Care. Nevertheless, it is probable that more involvement and dynamism can be achieved if new programs further insist on the importance of caring for patients with mental disorders and encourage health workers in PCC to do so. While GPs reported treating outpatients with mental disorders, this aspect is not reflected in their daily records, because few cases with these diagnoses were registered. This contradiction may be due to the stigma that physicians have towards mental disorders so they avoid treating them. Additional knowledge about antidepressant drugs and their use is needed.

Regarding the screening tool, there are positive results indicating that the $\mathrm{K}-10$ is useful for primary care. Of all the patients that were interviewed by the psychiatrist, $91.97 \%$ had a psychiatric diagnosis; only $8.03 \%$ of subjects with a K-10 score higher than 21 points showed no clinical diagnoses. This allowed us to reach to two important conclusions: (1) The K-10 is a sensitive and easy screening tool, and it is necessary to insist on its routine use in primary care, and (2) At least $50 \%$ of mental conditions of patients at PCC are not identified by the GPs, so the need for changes in the way to identify and give attention for mental disorders is evident. 
On the other hand, afraid and avoidance to treat a person with mental disorder by health personnel is one of the multiples barriers to attend mental disorders in the PCC; our results are the same reported by other investigators (Mora-Ríos and Bautista, 2014; Mascayano Tapia et al., 2015).

This paradigm shift in mental healthcare at the primary healthcare should be a priority for health systems worldwide, especially in countries where there are not enough psychiatrists, that is, developing countries. In these places, Collaborative Care model can make a difference.

Overall, our results showed and confirmed the same administrative barriers for mental health care in primary settings. Examples include poor funding to these levels of healthcare, excessive workload and lack of health professionals who are qualified to provide this care (Saraceno et al., 2007).

While there is still no categorical answer of the utility of the Collaborative Care model, this is a new form of care for mental health within the community, amending the models conventionally used in the primary healthcare, which are outdated and obsolete, so it can be considered as a new paradigm of mental healthcare in PCC in this country.

\section{Acknowledgments}

The authors wish to express their acknowledge to the patients, the Chief executive of Coyoacan, Martha E. Mandujano, and to the directors and personnel of participating PCC. To Dr. Maria Elena Medina-Mora for her review and suggestions. To Dr. Emmeline Lagunes-Cordoba for her review on the translation of the manuscript.

\section{Financial Support}

No financial support is reported by authors.

\section{Conflicts of Interest}

None.

\section{References}

Berenzon, S., Saavedra, N., Medina-Mora, M.E., Aparicio, V. and Galván, J. 2013: Evaluación del sistema de salud mental en México: ¿Hacia dónde encaminar la atención de la salud mental? Revista Panamericana de Salud Pública 33, 252-58.

Primary Health Care Research \& Development 2017; 18: 227-234
Borges, G., Medina-Mora, M.E., Wang, P.S., Lara, C., Berglund, P. and Walters, E. 2006: Treatment and adequacy on treatment of mental disorders among respondents to the Mexico National Comorbidity Survey. American Journal of Psychiatry 163, 1371-378.

Bower, P. and Gilbody, S. 2005: Managing common mental health disorders in primary care: conceptual models and evidence base. British Medical Journal 330, 839-42.

Gask, L., Sibbald, B. and Creed, F. 1997: Evaluating models of working at the interface between mental health services and primary care. British Journal of Psychiatry 170, 6-11.

Heinze, G., Chapa, G.C., Santisteban, J.A. and Vargas, I. 2012: Los especialistas en psiquiatría en México: su distribución, ejercicio profesional y certificación. Salud Mental 35, 279-85.

Katon, W., Von Korff, M., Lin, E. and Simon, G. 2001: Rethinking practitioner roles in chronic illness: the specialist, primary care physician and the practice nurse. General Hospital of Psychiatry 23, 138-44.

Lara, C., Medina-Mora, M.E. and Borges, G. 2007: Social cost of mental disorders: Disability and work days lost. Results from the Mexican survey of psychiatric epidemiology. Salud Mental 30, 4-11.

Mascayano Tapia, F., Lips Castro, W., Mena Poblete, C. and Manchego Soza, C. 2015: Estigma hacia los trastornos mentales: características e intervenciones. Salud Mental 38, 53-58.

Medina-Mora, M.E., Borges, G., Lara, C., Blanco-Jaimes, J., Fleiz-Bautista, C., Villatoro-Velázquez, J., Rojas-Guiot, E., Zambrano-Ruiz, J., Casanova-Rodas, L. and AguilarGaxiola, S. 2003: Prevalencia de Trastornos Mentales y uso de servicios: Resultados de la Encuesta Nacional de Epidemiología Psiquiátrica en México. Salud Mental 26, $1-16$.

Mora-Ríos, J. and Bautista, N. 2014: Estigma estructural, género e interseccionalidad. Implicaciones en la atención a la salud mental. Salud Mental 37, 303-12.

Saraceno, B., van Ommeren, M., Batniji, R., Cohen, A., Gureje, O., Mahoney, J., Sridhar, D. and Underhill, C. 2007: Barriers to the improvement of mental health services in low-income and middle-income countries. Lancet 370, 1164-174.

Vargas-Terrez, B.E., Villamil-Salcedo, V. and Pérez-Romero, J. 2012: Los modelos de atención primaria en salud mental: el caso de México. Atención Primaria 44, 441-42.

Vargas-Terrez, B.E., Villamil-Salcedo, V., Rodríguez-Estrada, C., Pérez-Romero, J. and Cortés-Sotres, J. 2011: Validación de la escala Kessler 10 (K-10) en la detección de depresión y ansiedad en el primer nivel de atención. Propiedades psicométricas. Salud Mental. Salud Mental 34, 323-31.

Villamil-Salcedo, V. 2011: Prevención y manejo comunitario de los Trastornos Mentales. In Sentíes Castellá, H., editor Psiquiatría para médicos no psiquiatras. Mexico City: Editorial Médica Panamericana, 281-92.

World Health Organization 2010: MhGAP Intervention Guide for mental, neurological and substance use disorders in nonspecialized health settings. Geneva. p. 107. 